This item was submitted to Loughborough's Research Repository by the author.

Items in Figshare are protected by copyright, with all rights reserved, unless otherwise indicated.

\title{
Developing a conceptual model for police custody in the UK
}

PLEASE CITE THE PUBLISHED VERSION

https://doi.org/10.1109/WSC.2018.8632227

VERSION

AM (Accepted Manuscript)

LICENCE

CC BY-NC-ND 4.0

\section{REPOSITORY RECORD}

Callaghan, Heather, Lisa M. Jackson, Sarah J. Dunnett, and Antuela A. Tako. 2019. "Developing a Conceptual Model for Police Custody in the UK”. figshare. https://hdl.handle.net/2134/36775. 


\title{
DEVELOPING A CONCEPTUAL MODEL FOR POLICE CUSTODY IN THE UK
}

\author{
Heather Callaghan \\ Lisa Jackson \\ Sarah Dunnett \\ Antuela A. Tako \\ Loughborough University \\ Epinal Way, Loughborough \\ LE11 3TU, UK.
}

\begin{abstract}
The reduction of police officers in UK forces in recent years has reduced the number of staff in police custody, hence it is imperative that staff, and other resources, are utilized appropriately to optimize the custody process. This work aims to develop a simulation model that looks at resource utilisation in police custody. Resource availability can be modelled and tested using discrete event simulation. Developing an accurate conceptual model is a key stage to link the real-world problem and the simulation model. There is minimal literature presenting an accurate police custody conceptual model and hence, that is the focus of this paper. The key sources of information for constructing this model, previous literature, custody record analysis and a custody suite visit are discussed. A final conceptual model is presented with a discussion of how this will be converted into a simulation.
\end{abstract}

\section{INTRODUCTION}

The budget cuts facing Police Forces in the UK have been widely publicized as has the decreasing number of police officers (Home Office 2017). With shrinking numbers of resources, it is becoming increasingly necessary to distribute and manage these resources effectively to meet demand. One of the areas that has suffered due to the budget cuts is police custody. As can be determined from the reports of unannounced inspections undertaken in custody suites in the East Midlands, a region of the UK. Some of the observations made such as, 'staffing was not always sufficient to meet the needs of all detainees' and 'there were delays in answering cell call bells because staff on duty were busy' (HMIP and HMIC 2014), imply that there are insufficient resources to deal with the demand in police custody. The availability of staff, as highlighted by the reports, is one of the factors affecting the efficiency of the custody process in the UK.

Simulation is a computer-based model that mimics a real-life situation and allows the user to alter various parameters to see how the system behaves under various circumstances (Law 2007; Robinson 2004; Pidd 2004). To develop a model, a system can be broken down into the service receiver (in this case, detainees), resources (such as the cells and staff) and the tasks that occur (e.g. booking-in, interviewing etc,). If no resources are available for a particular task, the service receivers will start/join a queue. There are various simulation methods, including agent-based modelling, continuous modelling and discrete event simulation. The latter is used in this study. Discrete event simulation works by modelling a series of sequential timed activities. Once one activity has been completed, the simulation will move onto the next activity until the service receiver has completed all the relevant activities and exited the system. The length of time taken to complete each activity is usually based on statistical distributions that accurately imitate 
the length of time spent in the system. Due to the sequential processes used and the repetitive stages of police custody, discrete event simulation is the most appropriate simulation method. When considering the resource management of police custody, testing different scenarios through a simulation model will give a more complete view of the options and evidence when making recommendations to the police.

Whilst the literature surrounding police custody in terms of resource management is limited, there has been extensive research into the resource management of emergency departments (Saunders et al 1989; Brenner at al 2010). It can be argued that this work is relevant to this research as an emergency department and police custody share many similarities. They are both parts of public sector organisations that serve members of the public and are open 24 hours a day, 7 days a week. The people they serve are there temporarily - a patient is kept in the emergency department until they are examined and then either allowed home or kept and transferred to a more permanent ward. In police custody, a detainee is kept until they can be processed and then either released or transferred to court. Despite these similarities, there are clear differences which requires work specific to police custody, for example, the arrival process. To enter a police custody suite a person must be arrested by an officer and brought in, this limits arrival rates to be dependent on the number of officers working, whereas in an emergency department anyone can arrive at any time. Simulation has been applied in various manners to accident and emergency departments - to evaluate the performance and effectiveness of departments and the influencing factors (Gunal and Pidd 2006), to aid in decision making when deciding between different procedures within the system (Connelly and Bair 2004) and in better scheduling staff in order to meet demand (Rossetti et al. 1999), just to name a few. Simulation could be applied in a similar way for police custody, however, before a computer simulation model can be developed, it is essential to have a detailed, current conceptual model of police custody.

There are a multitude of methodologies associated with the steps followed to developing a simulation model (Pidd 2004; Robinson 2004; Law 2007). These methodologies tend to share characteristics (Tako 2011), however not all have a clear conceptual modelling stage. In summary, based on these studies the main steps followed in a simulation study are: problem definition, conceptual modelling, data collection and analysis, model building, verification and validation, experimentation and implementation (Tako 2011).

We next consider, in more detail, the steps followed in developing a conceptual model for a model of police custody.

\section{INITIAL SIMULATION STAGES}

Existing literature specifically on police custody simulation is sparse. This has meant that we had to pay specific attention to conceptual modelling, before developing and evaluating a simulation model to ensure that an accurate conceptual model is developed. A summary of the steps are:

- Definition of Study Objectives

- System Boundary Definition

- Conceptual Model Formation

These are next followed to explain the initial steps followed to developing the police custody conceptual model.

\subsection{Definition of Study Objectives}

The objective of this study is to determine how best resources can be managed in police custody using a discrete event simulation approach. Police custody is a where an arrested person, referred to as a detainee is held and processed during the investigation into a crime. Their details are taken as well as their fingerprints and DNA where required and they may be subject to an interview. Police custody usually 
occurs in a purpose-built building called a custody suite which is built with a combination of individual cells where detainees are kept, interview rooms and booking areas. The staff in a custody suite are a mixture of police officers, custody sergeants and inspectors, and civilians, referred to as detention officers. The stages of custody being studied are those that take place within a custody suite, so will not include the initial arrest on the street and what occurs after the detainee has left the custody suite, such as in court. The resources that are being modelled are the staff in police custody, the custody sergeants and detention officers, and the cell capacity. These will form the primary inputs to the model, the numbers available etc. and the outputs monitored will be any results that are believed to have an impact on these, such as the overall time in police custody. For example, if a detainee is being held for an excessive period of time, this can affect cell availability and the utilization of staff. The model will also aim to take into account daily and seasonal variations by using time-dependent arrival rate so as to accurately model the demand.

\subsection{System Boundary Definition}

Defining system boundaries is driven based on the study objectives (Robinson 2008; Kotiadis et al 2014). Based on the objectives discussed above, this stud considers all the processes used in police custody starting with the initial arrival of the detainee at the custody suite to their eventual release, and what resources are required for each process and how this can impact the capacity and running of the custody suite. The resources will be treated as a variable input.

\subsection{Conceptual Model Formation}

A conceptual model can be defined as '.... n non-software specific description of the computer simulation model (that will be, is or has been developed), describing the objectives, inputs, outputs, content, assumptions and simplifications of the model.' (Robinson 2008). A conceptual model is one of the most important stages of a simulation study as it is essentially a bridge between the real-world problem and the computational simulation model. It is important to focus on including the stages that are relevant to the aims of the model and not include unnecessary information and consequently overcomplicate the simulation model and produce excessive data. Developing a conceptual model is also an iterative process, it often requires developing and improving through the simulation process. Soft system approaches have been used is discrete event simulation previously to understand the problem situation and the objectives of the simulation study (Lehaney and Paul 1996; Kotiadis 2007). A combination of using hard and soft approaches to developing a simulation model is proposed in the PartiSim approach (Kotiadis et al 2014; Tako and Kotiadis 2015) and a similar approach has been taken in this project. The conceptual model was developed through the following 3 stages:

- Previous Research

- Custody Records

- Custody Visit

The previous research information was used as it is readily available and is based on a literature search for any models that have been developed for police custody previously. The custody records are the only data recorded by custody stations of the processes and order of the processes a detainee goes through, so they were examined for detail. a series of over 80 recent custody records from a regional UK police force were analyzed. the custody visit involved a tour of a custody suite in a different UK police force.

By including information from a custody visit and custody records, in addition to previous research, this helps to make the conceptual model more robust. The custody records provide a view to each of the stages included in custody and the order they are performed in, as time were provided for each task. The custody tour provided current, first-hand data, which helped to fill in the gaps in stages that may not be recorded in the system. This approach gives the researcher a more complete picture of the occurrences in police 
custody in order to better inform a conceptual model and also allows the researcher to see the process firsthand as opposed to solely relying on data collected or recorded by others.

\section{DEVELOPING THE CONCEPTUAL MODEL}

In this section, an outline of how the final police custody process map was developed will be presented. Each stage of research will be detailed, and an improved conceptual model will be included. The discussion of previous research will be used as a starting point for the model, followed by the custody records and, finally, a visit to a custody suite. The custody records were examined to update the previous research as this research was conducted quite a few years ago. A visit to a custody suite then followed to verify the information first hand and to ensure any stages and tasks not recorded in the previous research or custody record data was included.

\subsection{Previous Research}

The first stage to constructing this conceptual model was analyzing previous literature regarding simulation in police custody and the stages that were identified in those articles. The literature regarding police custody where a simulation model, and hence a conceptual model, has been developed is minimal. In an early study, (Greasley and Barlow 1998) published a simulation model used in resource allocation. This model had the following stages in the custody process after the arrival of a detainee, as shown in Figure 1: the booking in process after arrival where the detainees information is taken and the crime they are being arrested for; the initial detention whilst evidence is being gathered, the interview with the investigating officer; a charging which is decision on whether the detainee will be charged with the crime and possible consequent detention or bail. Detention would mean the detainee is held further until transport to court can be arranged and bail would allow the detainee to leave the police station. This model was used in BPR, business process reengineering, of the roles of staff in police custody.

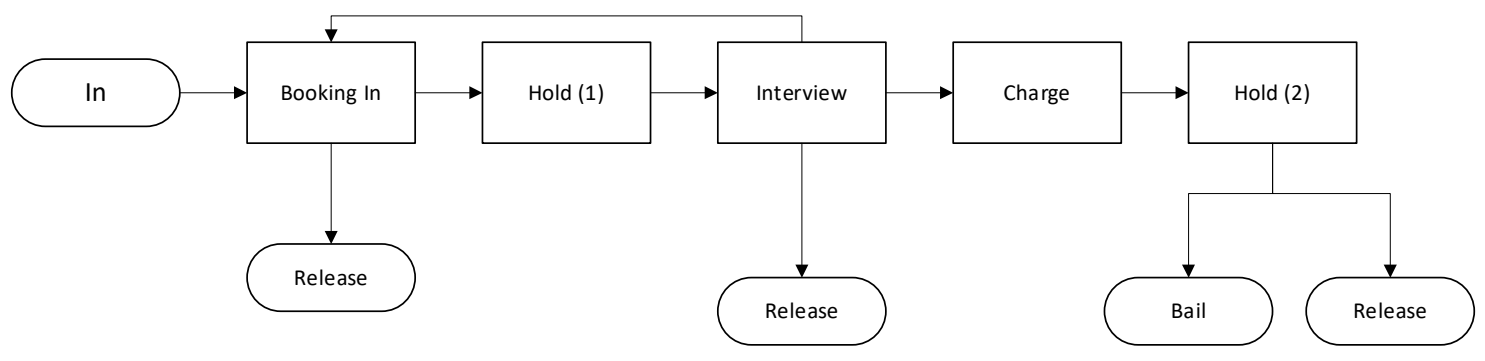

Figure 1: Process map of Police Custody (Greasley 1998).

In two further studies in 2000 and 2001, Greasley utilized a more detailed conceptual model of the arrest process as shown in Figure 2, which also covered police custody. The previous 'In' stage from Figure 1 has been expanded to include the search of the detainee at the location when they are first arrested and the transport arrangements to take the detainee to the custody suite. The book-in stage has been further detailed to incorporate the possibility of being released, a search and a DNA test. The interview, holding and charge stages have remained essentially the same. The final release stage has been continued beyond police custody to take into account the court. This model considers the possibility that not all detainees will experience every stage of the process and the staff roles involved at each stage. This is important to include when considering resource utilization and distribution as staff are a key resource. A minor issue with these models is that a detainee appears to go straight from DNA test to an interview which seems unlikely, particularly if a detainee is under the influence or behaving violently.

Whilst these models are relevant, this work was published over a decade ago and there have been several policy and procedural changes over the time that may have affected the stages of police custody, 
for example the introduction of the Safer Detention and Handling of Persons in Police Custody in 2006, which was updated again in 2012 (National Police Improvement Agency 2012). Due to these changes, it would be prudent to update the conceptual model from previous research and to tailor them for this research. In order to accurately model the resources in police custody, the details of the booking in process should ideally be included in conceptual model so as to determine what tasks are performed by which members of staff. Understanding the roles of the staff working in police custody is key to determine the availability and utilization levels of staff as a resource. One of the issues with this model, in regard to this work, is that the only task assigned to the custody officer is the initial book-in stage. It would also be preferable to include what non-police resources are available, as delays in accessing them may slow the system down; including them and their role in the conceptual model will give a better idea as to what extent external resources are used in police custody.
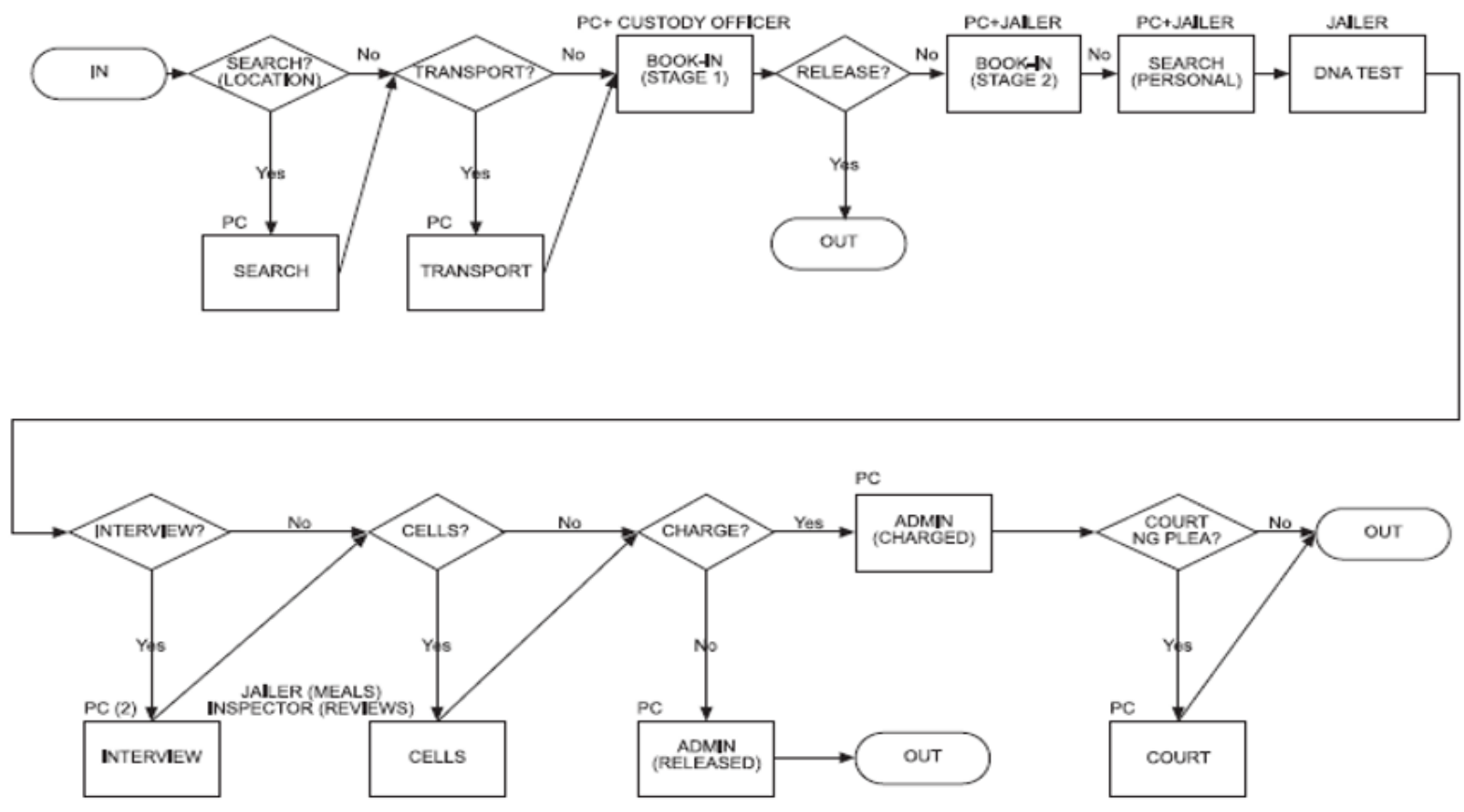

Figure 2: Process map of Police Custody (Greasley 2001).

The aims of a conceptual model should be aligned with those of the simulation study, so the conceptual model should be tailored to meet the eventual aims of the project (Robinson 2008). The aims of this project are focused on resource utilization within a custody suite. The conceptual models from the previous research can be adapted for this research (Figure 3). The search at the location and arranging transport included in Figure 2 are not relevant to this project as these stages take place outside of police custody, and the aims of this project are to examine the resources within a custody suite. These stages have been reduced to 'Arrested and Taken to Police Station'. The book-in stages from Figure 2 have been included as has the interview stage from Figures 1 and 2. If an interview is not required, the detainee will remain in the cell so there will be no change to resources required so the cell stage from Figure 2 has been excluded. The charge stages from Figures 1 and 2 have been condensed as the detainee must be processed out of police custody regardless of whether they are being released to a court or released entirely. The stages of being released or taken to court from Figure 1 and 2 have been used as the end of the model. The court stage from Figure 2 has been removed as this takes place outside of custody. 
Callaghan, Jackson, Dunnett, and Tako

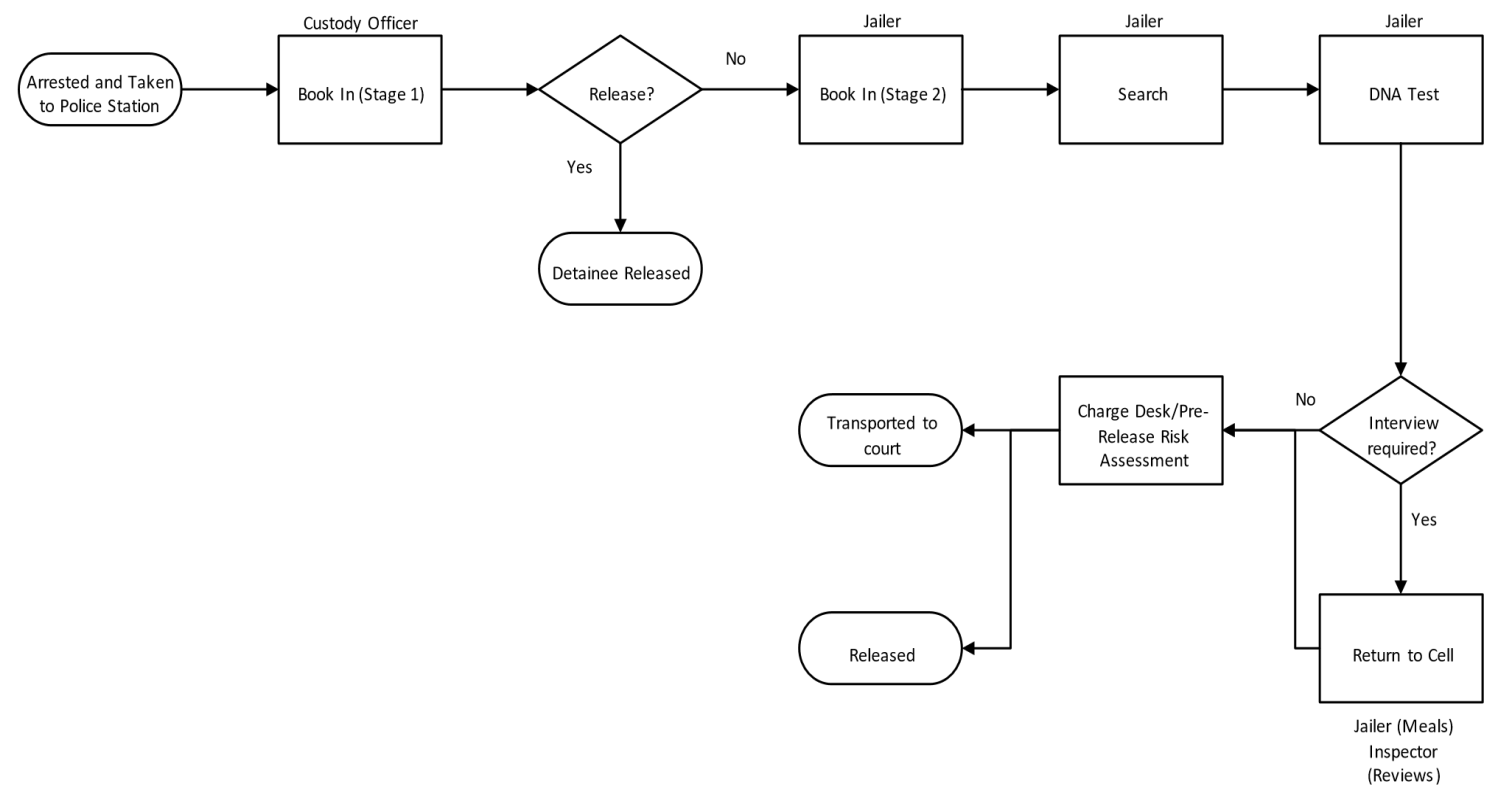

Figure 3: Process map of Police Custody - First Iteration.

\subsection{Custody Records}

The next step taken to improve on this model was to include information gathered from recent custody records provided by a regional UK police force. These records were gathered from the custody record management system of a regional police forces custody suites. The custody records are the recorded data of the processes a detainee experiences while in police custody and the variation in those experiences. This allowed more stages to be included and it also provided a clearer picture as to the order of these stages and the various pathways detainees can take.

From these records it was determined that one of the tasks performed by staff not included in the previous model is the observational checks. When a detainee arrives at a custody suite, a risk assessment is performed to determine how much risk a detainee is considered to be to themselves and others. They are consequently assigned an observation level which requires them to be either under constant supervision or for staff to periodically check on them. Depending on the number of detainees in custody, this can considerably increase staff utilization and should be included in the conceptual model for this purpose. From the records it was identified that the booking in process was broken down into more detailed stages than shown in the previous models in Figures 1 and 2. Hence, we include an additional process of risk assessment which determines whether medical attention or an appropriate adult is required, as well as an initial search and detention authorization. The detention of any person must be authorized by a custody officer after the arresting officer has presented the reason for arrest so as no one is detained without valid reason. These additional stages recorded may impact the use of resources such as the medical room. If a detainee requires medical attention, they need to be escorted to the medical room which would require a member of staff to be present. Also, if the detainee is underage or considered to be mentally vulnerable there may be further delays in the process as it often requires time for social care to be arranged and/or an adult to arrive.

The conceptual model from 3.1 is updated to include these stages as shown in Figure 4. All previous references to Jailer have been changed to Detention Officer as this is now the terminology used for this position. The Book-In (Stage 1) has been changed to give a more accurate description - a personal search. The terminology has been altered in the next stage, from Release to Detention Authorized, although it is the same process. The Book-In (Stage 2) has also been altered to be more descriptive and the possibility of Medical attention and appropriate adult has been added. The risk assessment and DNA/Livescan have been 
put in the same stage as they don't appear to be performed in any particular order. This could be a case of what equipment is free at the time. The search stage has been altered to Strip search as this is the further search indicated in the records, this has also been made an optional stage as these kinds of searches are only performed where necessary. An 'Escort to Cell' stage has been added to include the staffing tasks of performing observational checks on detainees.

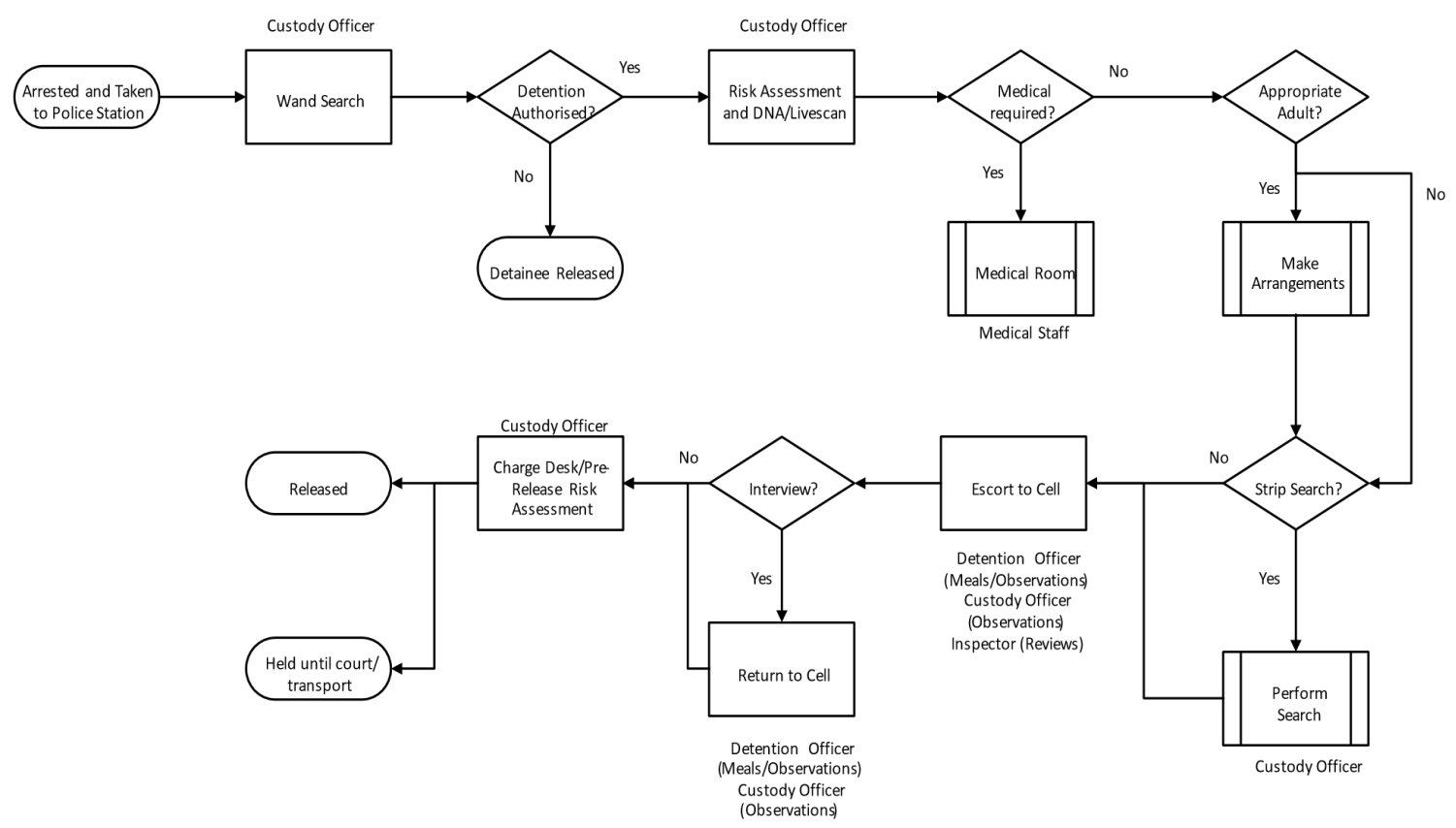

Figure 4: Process Map of Police Custody - Second Iteration.

\subsection{Custody Visit}

Following the analysis of custody records, a visit to a police custody suite in the East Midlands to observe the custody process took place, which informed further iterations of the conceptual model. This helped to ensure the model was up to date and to take into account any policy changes as well as any stages that didn't previously appear in the previous literature or records. This visit was arranged on a weekday in the late morning as staff explained that this was usually an off peak time and would provide more opportunity for discussion. During this visit, the researcher was shown around the station and had the opportunity to question staff and ask their opinion about resourcing issues and the overall custody process. This not only provides information to develop the conceptual model but also to further refine the study aims for later parts of the study. Although the information gathered from this visit is relevant to the suite visited, further arrangements for similar research will be carried out at other suites to validate the research.

From the explanations of the custody suite process provided by the staff, it became obvious that the first stage, as a detainee arrives at a custody suite is placed in a holding cell whilst initial paperwork is completed before being escorted to the booking desk. This is a stage that should be included in the model as it contributes to a time delay before the detainee is booked in. Also the holding cells act as a waiting room, which limits the capacity as there are a set amount of holding cells. When the custody suite has reached capacity, the staff refuse to accept any more detainees and they are taken to another custody suite. The staff also explained that if a detainee arrives who has been arrested on a charge that requires an intoxication reading, such as drink driving, they are given priority in the 'queue' waiting to be booked in and are processed as soon as possible so as they can have the alcohol level tested quickly to provide a more 


\section{Callaghan, Jackson, Dunnett, and Tako}

accurate reading. Some distinction is also needed between male and female staff members as female detainees should only be processed, escorted and searched by female members of staff.

In light of this information, a third iteration of the process map was undertaken which resulted in the process map shown in Figure 5. A holding cells stage has been added, as has a drink driver possibility. All of the custody sergeant and detention officer labels have been altered to include gender. The book-in process, the interview and the release remain the same as in the previous process model (Figure 4).
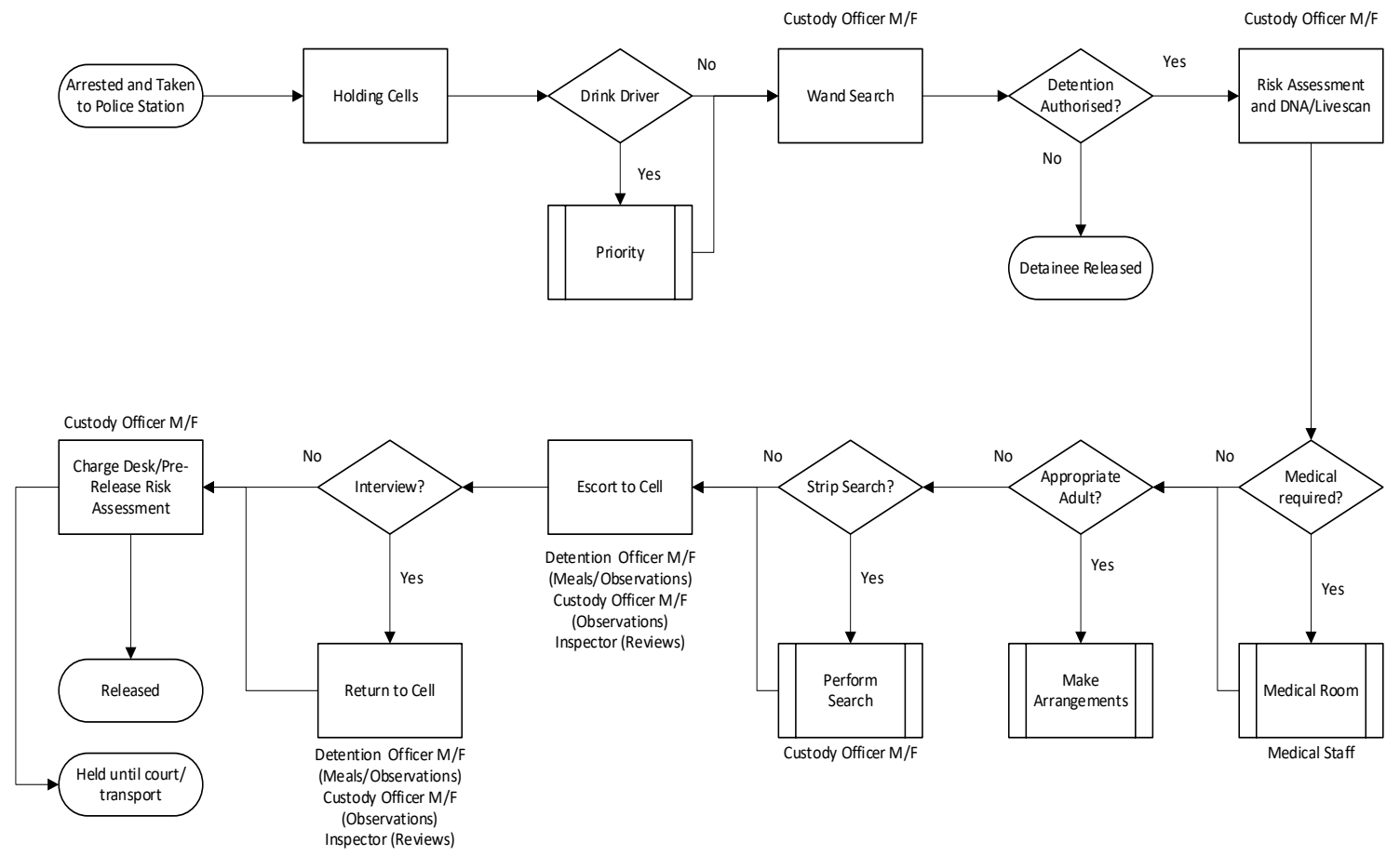

Figure 5: Conceptual Model of Police Custody - Third iteration.

\section{CONCLUSION AND NEXT STAGES}

Developing a conceptual model is a key but least understood stages of a simulation study (Law 1991). A conceptual model is the initial bridge between the real-world situation and the computer model. The final conceptual model for the UK police custody process is presented in Figure 5 and was developed by taking previous research and updating and tailoring it through previous custody records and a visit to a custody suite. The data records and the custody suite were force specific and it is possible that in other forces, some of the stages may occur in a different order and that the tasks performed by different staff roles with custody may vary, a possibility that will be further explored through observations that are planned to take place in multiple custody suites in different forces. However, this conceptual model provides a reasonable basis to begin developing a computer simulation to model the resources in police custody, which is the main aim of this project.

The steps followed in this study include: definition of study objectives, system boundary definition, conceptual model development, data collection and analysis, model building, experimentation and implementation of findings. Furthermore, verification and validation takes place throughout all the stages of the project. A roadmap of these steps is presented in Figure 6, along with the intended data sources that will be utilized.

The first three stages of this study, study objectives, system boundary definition and conceptual model formation, have been described in this paper. Previous literature, the qualitative aspects of the custody data records and the custody visit have all been used to inform the conceptual model. The accuracy of this model 


\section{Callaghan, Jackson, Dunnett, and Tako}

will be verified through a series of observations in multiple police custody suites. These observations will also aid in discovering any discrepancies in the custody process between different forces. Through these steps we are looking to ensure that the conceptual model developed fulfils the following criteria: accuracy (is the model sufficiently accurate for the purpose at hand?), utility for the police force (can it lead to a model that is useful to aid decision making?) and feasibility (can it be developed into a computer model?) (Robinson 2008).

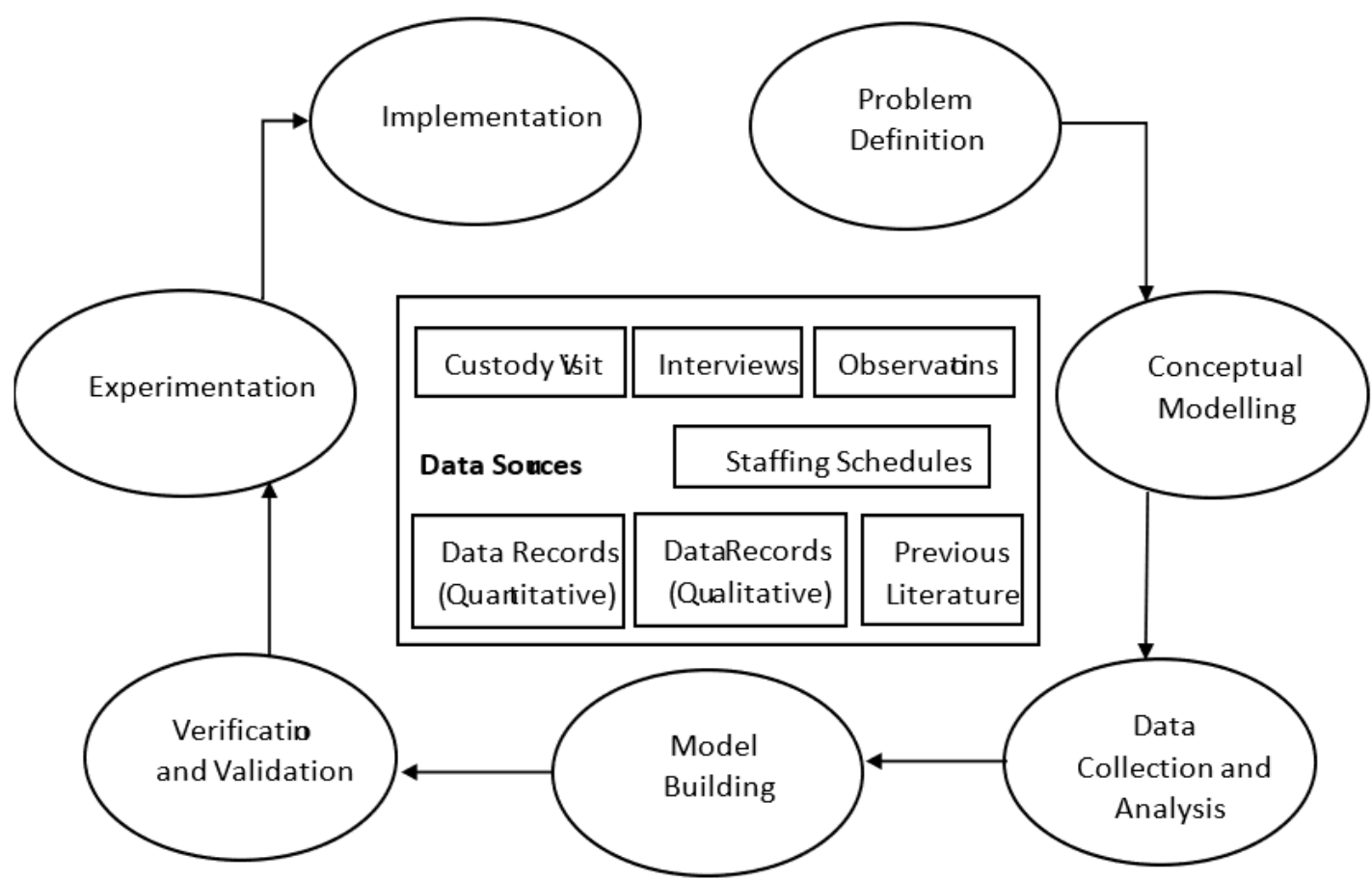

Figure 6: Roadmap of the next stages of the study.

The next steps to be followed include: data collection and analysis, model building, experimentation and implementation of findings. In constructing the conceptual model for police custody, an indication of the data available for the simulation model has been obtained, particularly from the custody record analysis. It has provided some quantitative data that can be used when translating the model to a computer-based model. The data collection has begun simultaneously with the conceptual model, however further data needs to be collected from custody records. More specifically, accurate timings of each of the stages detailed in the conceptual model, detailed staffing schedules of each of the staff roles identified and demographic and criminal data regarding the detainees. From conversations with the police forces we are in contact with, we are under the understanding that this information is recorded, and permission has been granted for the research team to collect this data.

Using this information and the conceptual model, a computer-based simulation model will subsequently be built. To verify and validate this model, both the simulation model and conceptual model will be presented in interviews with staff working within police custody to discuss the accuracy and any shortcomings. The experimentation stage will test various resource levels and distribution strategies, such as staffing schedules, to determine the resulting optimal scenario. These scenarios will also be discussed with police as to the validity of the optimal scenario. Frameworks such as PartiSim (Tako and Kotiadis 2015) may be applicable to guide our interactions with the police staff. It is anticipated that experimentation could consider altering demand levels to explore how the system copes under varying levels of pressure. Historical data has shown a consistent fall in the number of detainees been brought into police custody 
(National Statistics 2017) however there has been little work done on predicting the future arrest rates. As arrest rates have a direct impact on the busyness of custody suites, combining the simulation model with a forecasting model it is considered to give a better indication into future issues that may arise within custody, which this study will aim to develop.

It is expected that a recommendation will be made to the police based on these results regarding how their resources are being distributed and if they can be better used. This could be in the form of recommending using a different staffing schedule, better distribution of detainees between suites within a force during peak times, etc. Consequently, it is important to ensure the initial stages, particularly the conceptual model, are thoroughly explored. This comprehensive conceptual model has been developed to ensure that an accurate future evaluation with the simulation model.

\section{REFERENCES}

Brenner, S., Z. Zeng, Y. Liu, J. Wang, J. Li, and P.K. Howard. 2010. "Modeling and Analysis of the Emergency Department at University of Kentucky Chandler Hospital using Simulations". Journal of Emergency Nursing, 36(4):303-310.

Connelly, L. G., and A.E. Bair. 2004. "Discrete Event Simulation of Emergency Department Activity: A Platform for System-Level Operations Research". Academic Emergency Medicine, 11(11):1177-1185.

Greasley, A., and S. Barlow. 1998. "Using Simulation Modelling for BPR: Resource Allocation in a Police Custody Process". International Journal of Operations \& Production Management, 18(9/10):978-988.

Greasley, A. 2000. "A Simulation Analysis of Arrest Costs". Journal of the Operational Research Society, 51(2):162-167.

Greasley, A. 2001. "Costing Police Custody Operations". Policing: An International Journal of Police Strategies \& Management, 24(2):216-227.

Gunal, M., and M. Pidd. 2006. "Understanding Accident and Emergency Department Performance using Simulation". In Proceedings of the 2006 Winter Simulation Conference, edited by L.F. Perrone et al., 446 - 452, Piscataway, New Jersey: IEEE.

HMIP and HMIC. 2014. "Report on an Unannounced Inspection Visit to Police Custody Suites".

Justice Inspectorates.

Home Office. 2017. "Police Workforce, England and Wales, 31 March 2017". London.

Kotiadis, K. 2007. "Using Soft Systems Methodology to determine the Simulation Study Objectives". Journal of Simulation, 1(3):215-222.

Kotiadis, K., A.A. Tako, and C. VasilakiS. 2014. "A Participative and Facilitative Conceptual Modelling Framework for Discrete Event Simulation Studies in Healthcare". Journal of the Operational Research Society, 65(2):197-213.

Law, A.M. 1991. "Simulation-Models Level of Detail determines Effectiveness". Industrial Engineering, 23(10):16.

Law, A. M., W.D. Kelton, and W.D. Kelton. 2007. Simulation Modelling and Analysis. ${ }^{\text {nd }}$ Edition. New York: McGraw-Hill.

Law, A. M. 2009. "How to build Valid and Credible Simulation Models". In Proceedings of the 2009 Winter Simulation Conference, edited by M.D. Rossetti et al., 24 - 33. Piscataway, New Jersey: IEEE.

Lehaney, B., and R.J. Paul. 1996. "The Use of Soft Systems Methodology in the Development of a Simulation of Out-Patient Services at Watford General Hospital". Journal of the Operational Research Society, 47(7):864-870.

National Policing Improvement Agency. 2012. "Guidance on the Safer Detention and Handling of Persons in Police Custody". Home Office.

National Statistics. 2017. "Police Powers and Procedures England and Wales". Home Office.

Pidd, M. 2004. Systems Modelling: Theory and Practice. $1^{\text {st }}$ Edition. Chichester: Wiley.

Robinson, S. 2004. Simulation: The Practice of Model Development and Use. Chichester: Wiley. 
Robinson, S. 2008. “Conceptual Modelling for Simulation Part I: Definition and Requirements”. Journal of the Operational Research Society, 59(3):278 - 290.

Rossetti, M. D., G.F. Trzcinski, and S.A. Syverud. 1999. "Emergency Department Simulation and determination of Optimal Attending Physician Staffing Schedules". In Proceedings of the 1999 Winter Simulation Conference, edited by P.A. Farrington et al., 1532-1540, Piscataway, New Jersey: IEEE.

Saunders, C.E., P.K. Makens, and L.J. Leblanc. 1989. "Modeling Emergency Department Operations using Advanced Computer Simulation Systems". Annals of Emergency Medicine, 18(2):134-140.

Tako, A. A. and K. Kotiadis. 2015. "PartiSim: A Multi-Methodology Framework to Support Facilitated Simulation Modelling in Healthcare". European Journal of Operational Research, 244(2):555-564.

Tako, A. A. 2011. "Model Development in Discrete-Event Simulation: Insights from Six Expert Modelers". In Proceedings of the 2011 Winter Simulation Conference, edited by S. Jain et al, 3928-3939, Piscataway, New Jersey: IEEE.

\section{AUTHOR BIOGRAPHIES}

HEATHER CALLAGHAN is a PhD research student at in the Department of Aeronautical and Automotive Engineering at Loughborough University. She holds a MSc in Mathematics of Cryptography from Royal Holloway, University of London. Her email address is H.A.Callaghan@1boro.ac.uk.

PROFESSOR LISA JACKSON is the Professor of Risk and Reliability in the Department of Aeronautical and Automotive Engineering at Loughborough University. Her main interests lie in reliability of engineering systems, system safety and enhanced service provision. Her email address is L.M.Jackson@lboro.ac.uk.

DR SARAH DUNNETT is a Senior Lecturer in Control and Reliability in the Department of Aeronautical and Automotive Engineering at Loughborough University. Her research interests include reliability of engineering systems and aerosol science. Her email address in S.J.Dunnett@1boro.ac.uk.

DR ANTUELA TAKO is a Reader in Operational Research at the School of Business and Economics, Loughborough University. She holds a PhD in Simulation and an MSc in Management Science and Operational Research from the University of Warwick. Her research interests include the comparison of simulation approaches (discrete-event simulation and system dynamics), facilitated and participative simulation modelling, conceptual modelling and health care modelling. She is Associate Editor of the Journal of the Operational Research Society. Her email address is a.a.takou@1boro.ac.uk and her webpage is: http://www.lboro.ac.uk/departments/sbe/staff/anthi-antuela-tako/. 